\title{
Etiology Profile of the Patients Implanted in the Cochlear Implant Program
}

\author{
Saroj Mali, Divij Sonkhya, Mohnish Grover, Nishi Sonkhya* \\ Department of ENT, SMS Medical College and Hospital, Jaipur, India \\ Email: ${ }^{*}$ drsonkhya@yahoo.co.in
}

Received 18 February 2015; accepted 24 May 2015; published 27 May 2015

Copyright (C) 2015 by authors and Scientific Research Publishing Inc.

This work is licensed under the Creative Commons Attribution International License (CC BY). http://creativecommons.org/licenses/by/4.0/

(c) (i) Open Access

\begin{abstract}
Hearing loss in children constitutes a considerable handicap because it is an invisible disability and compromises optimal development and personal achievement of a child. The period from birth to 5 years of life is critical for the development of speech and language; therefore, there is need for early identification and assessment of hearing loss and early rehabilitation in infants and children. Cochlear implants are the treatment of choice for patients with severe to profound sensorineural hearing loss. The goal of the present study was to investigate the different hearing impairment etiologies of patients implanted in cochlear implant program. The hospital based interventional study was conducted in the Department of Otorhinolaryngology, SMS Medical College, Jaipur from July 2011 to Dec. 2013. Present study included 60 prelingually deafened patients who attended ENT OPD and underwent cochlear implant. The most common cause of deafness in our study was acquired $(56.66 \%)$, which predominantly included perinatal risk factors $(64.70 \%)$, followed by prenatal risk factors $(41.17 \%)$. The second common cause was hereditary $(26.66 \%)$, followed by unknown (16.66\%). Infection and ototoxic drug history were the most common risk factors in prenatal and postnatal group. The most common perinatal cause was low birth weight and prematurity.
\end{abstract}

\section{Keywords}

Hearing Impairment, Cochlear Implant, Congenital Sensorineural Hearing Loss, Familial Hearing Loss, Syndromic Hearing Loss

\section{Introduction}

Hearing loss in children constitutes a considerable handicap because it is an invisible disability and compromis-

"Corresponding author.

How to cite this paper: Mali, S., Sonkhya, D., Grover, M. and Sonkhya, N. (2015) Etiology Profile of the Patients Implanted in the Cochlear Implant Program. International Journal of Otolaryngology and Head \& Neck Surgery, 4, $265-272$.

http://dx.doi.org/10.4236/ijohns.2015.43045 
es optimal development and personal achievement of a child. Hearing loss in a child may develop from causes before birth (prenatal), during birth (perinatal) or thereafter (postnatal). Prenatal causes may pertain to the infant or the mother. An infant may be born with inner ear anomalies due to genetic or nongenetic causes. Anomalies affecting the inner ear may involve only the membranous labyrinth or both the membranous and bony labyrinths, which include Sheibe's dysplasia, Alexander's dysplasia, Bing-Siebenmann dysplasia, Mondini's dysplasia, enlarged vestibular aqueduct and semicircular canal malformations. Maternal factors include infections, drugs during pregnancy, radiation to the mother in first trimester and other factors which include nutritional deficiency, diabetes, toxaemia and thyroid deficiency. Maternal alcoholism is also teratogenic to the developing auditory system. Infections which affect the developing foetus are Toxoplasmosis, Rubella, Cytomegalovirus, Herpes type 1 and 2 and Syphilis. Drugs like Streptomycin, Gentamycin, Tobramycin, Amikacin, Quinine or Chloroquine, when given to the pregnant mother, cross the placental barrier and damage the cochlea. Perinatal causes relate to those during birth or in early neonatal period and include anoxia, prematurity, low birth weight, birth injuries, neonatal jaundice (bilirubin level greater than $20 \mathrm{mg} \%$ damages the cochlear nuclei), neonatal meningitis, sepsis, time spent in neonatal ICU and ototoxic drugs. Postnatal causes include viral infections (Measles, Mumps, Varicella, and Influenza), meningitis and encephalitis. Other causes are secretory otitis media, ototoxic drugs, trauma including fracture of temporal bone, middle ear surgery or perilymph leak and noise induced deafness.

\section{Material and Methods}

Present study included prelingually deafened patients, who attended ENT OPD and underwent cochlear implant in Department of Otorhinolaryngology, SMS Medical College, Jaipur from July 2011 to Dec. 2013. 60 patients (age $2.5 \mathrm{yrs}-11 \mathrm{yrs}$ ) underwent cochlear implant in the study period. A detailed history was obtained in reference to prenatal, perinatal and post natal period to find out various risk factors for hearing loss. The etiological diagnosis was obtained by means of an interview carried with the parents and family members. We approached relevant issues such as problems during pregnancy (prenatal factors), problems during delivery and birth of the baby (perinatal factors), problems during postnatal period and hereditary factors associated with the current disease.

\section{Results}

The study included 60 patients, with male to female ratio of 1.72 and males contributing $63.4 \%$ and females were $36.6 \%$. The most common cause of deafness in our study was acquired $(56.66 \%)$, which predominantly included perinatal risk factors $(64.70 \%)$, followed by prenatal risk factors $(41.17 \%)$. The second common cause was hereditary (26.66\%), followed by unknown (16.66\%) (Table 1, Table 2 and Figure 1).

Considering the 14 cases which presented with prenatal risk factors, it was observed that Infection and ototoxic drug history was the most common prenatal risk factor. There were two patients who had congenital rubella syndrome (Table 3 and Figure 2).

Considering the perinatal factors, it was observed that low birth weight, birth asphyxia and prematurity were the important risk factors (Table 4). Infection with history of ototoxic drugs, and hyperbilirubenemia requiring phototherapy in neonatal period were the predominant postnatal factors, contributing $80 \%$ (Table 5 and Figure 3). $5 \%$ of our patients had Waardenburg's syndrome. The distribution of hearing loss in the syndromic verses nonsyndromic group is statistically highly significant (Table 6). 13 patients had family history of deaf-mutism, out

\begin{tabular}{|c|c|c|}
\hline \multicolumn{3}{|l|}{$\mathrm{n}=60$} \\
\hline Etiological factors for deafness & No. of patients & Percentage \\
\hline Unknown & 10 & 16.66 \\
\hline Acquired & 34 & 56.66 \\
\hline $\begin{array}{l}\text { Hereditary: familial (13 ) } \\
\text { syndromic (3) }\end{array}$ & 16 & 26.66 \\
\hline Total & 60 & 100 \\
\hline
\end{tabular}


Table 2. Acquired causes of deafness.

\begin{tabular}{ccc}
$\mathrm{n}=34$ & & \\
\hline Causes of hearing loss & No. of patients & Percentage \\
\hline Prenatal & 6 & 17.64 \\
Perinatal & 10 & 29.41 \\
Postnatal & 4 & 11.76 \\
Prenatal + perinatal & 6 & 17.64 \\
Perinatal + postnatal & 4 & 11.76 \\
Prenatal + perinatal + postnatal & 2 & 5.88 \\
Infant factor & 2 & 5.88 \\
Total & 34 & 100
\end{tabular}

Prenatal: 14 (41.17); Perinatal: 22 (64.70); Postnatal: 10 (29.41); Infant factor: 2 (5.88).

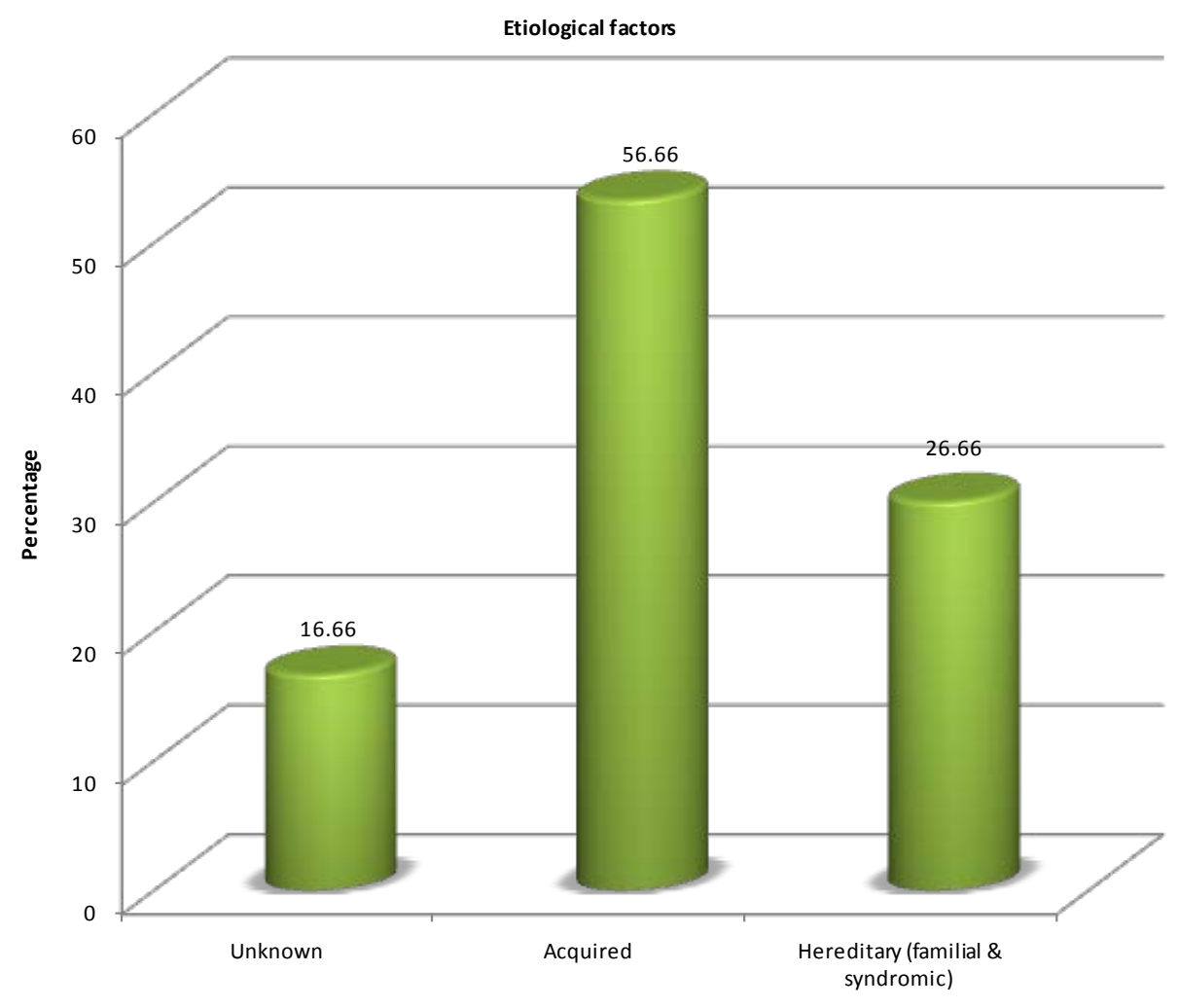

Figure 1. Showing etiological factors.

of them 2 patients had both maternal and sibling factors, these patients were included in sibling group, therefore, out of 13 cases of familial deafness, $69.23 \%$ of the patients were in the sibling group (Table 7).

\section{Discussion}

We have performed an institutional study which included prospective review of prelingually deaf children aged 2.5 to 11 years (60 cases), with bilateral severe to profound SNHL who derived minimal to no benefit from conventional amplification i.e. using hearing aid and underwent unilateral Cochlear Implant from July 2011 to Dec. 2013. In the present study of 60 patients, male to female ratio was 1.72 , with males contributing $63.33 \%$ and females were $36.66 \%$, this is in concordance with the gender distribution given by Calhau [1], in which 
Table 3. Distribution of prenatal risk factors.

\begin{tabular}{ccc}
$\mathrm{n}=14$ & No. of patients & Percentage \\
\hline Prenatal factors & 2 (rubella) & 14.28 \\
Torch group & 6 & 42.85 \\
Infection and ototoxic drug history (amikacin and tobramycin) & 2 & 14.28 \\
History of repeated abortion & 2 & 14.28 \\
Preeclampsia & 2 & 14.28 \\
History of abortion + preeclampsia & 14 & 100 \\
Total No. of patients & & \\
\hline
\end{tabular}

Table 4. Distribution of perinatal risk factors.

\begin{tabular}{ccc}
$\mathrm{n}=22$ & No. of patients & Percentage \\
\hline Perinatal factors & 8 & 36.36 \\
Low birth weight & 2 & 9.09 \\
Low birth weight + birth asphyxia & 2 & 9.09 \\
Low birth weight + prematurity & 2 & 9.09 \\
Low birth weight + birth asphyxia + prolonged labour & (forceps delivery) & 18.18 \\
Low birth weight + birth asphyxia + prematurity & 4 & 9.09 \\
Meconium aspiration & 2 & 9.09 \\
Meconium aspiration + low birth + prematurity & 2 & 100 \\
Total No. of patients & 22 &
\end{tabular}

Distribution of prenatal risk factors

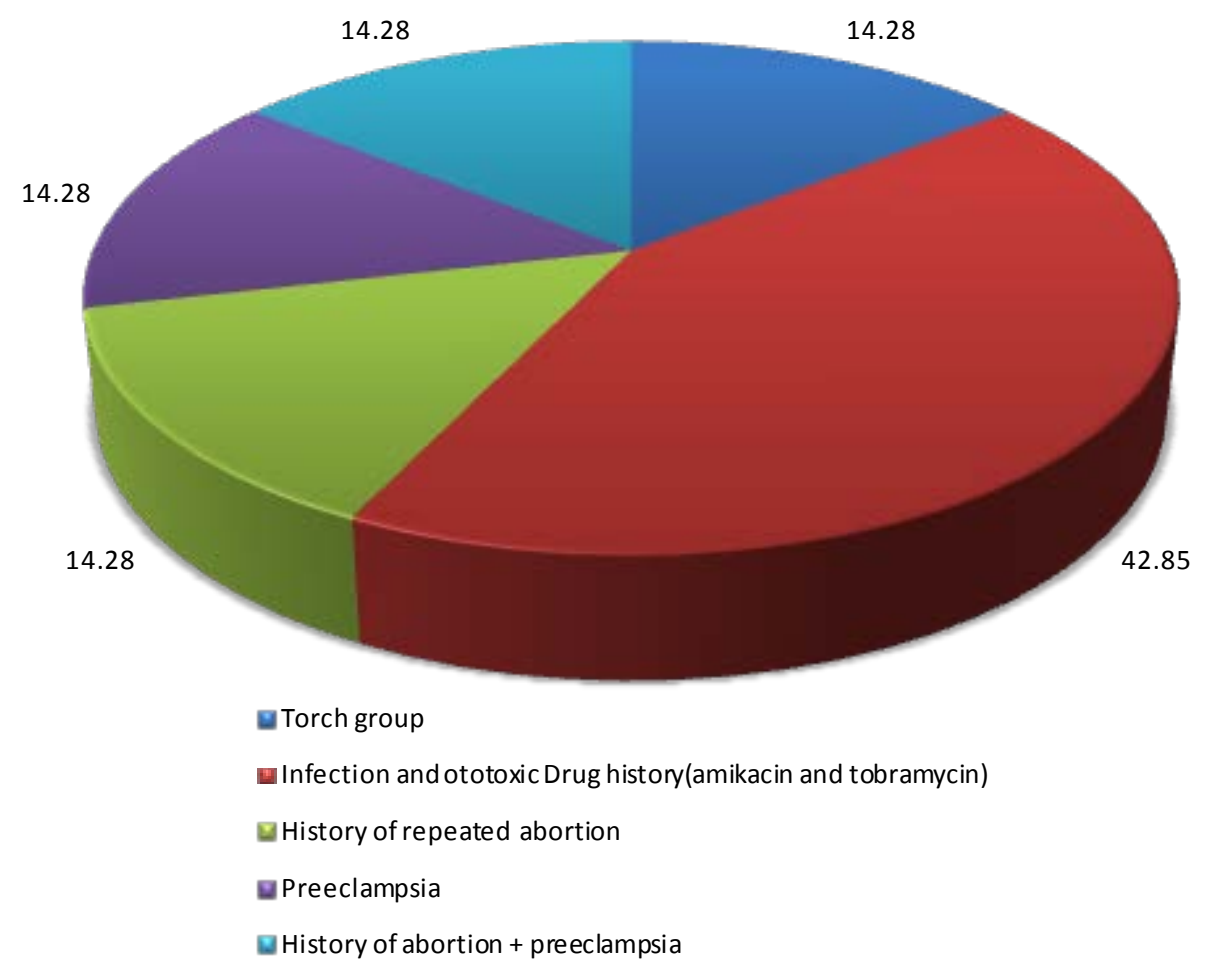

Figure 2. Distribution of prenatal risk factors. 
Table 5. Distribution of postnatal risk factors.

\begin{tabular}{cccc}
$\mathrm{n}=10$ & & & \\
\hline Postnatal factors & No. of patients & Percentage \\
\hline Viral infection & - & - & - \\
Infection and ototoxic drug history & 4 & 40 & \\
Infection with ototoxic drug history and hyperbilirubenemia & 2 & 20 & 80 \\
Hyperbilirubenemia requiring phototherapy & 2 & 20 & \\
Delayed milestones + ototoxic drug history & 2 & 20 \\
Total & 10 & 100 \\
\hline
\end{tabular}

Table 6. Syndromic/nonsyndromic hearing loss.

\begin{tabular}{cccc}
$\mathrm{n}=60$ & & & \\
\hline Hearing loss & No. of patients & Percentage & P value (Z test) \\
\hline Syndromic & 3 & 5 & \\
Nonsyndromic & 57 & 95 & $0.001(\mathrm{HS})$ \\
Total & 60 & 100 & \\
\hline
\end{tabular}

HS: Highly Significant

Table 7. Familial cases of deafmutism.

\begin{tabular}{ccc}
$\mathrm{n}=13$ & & \\
\hline Familial & No. of patients & Percentage \\
\hline Paternal & 2 & 15.38 \\
Maternal & 2 & 15.38 \\
Sibling & 9 & 69.23 \\
Total & 13 & 100 \\
\hline
\end{tabular}

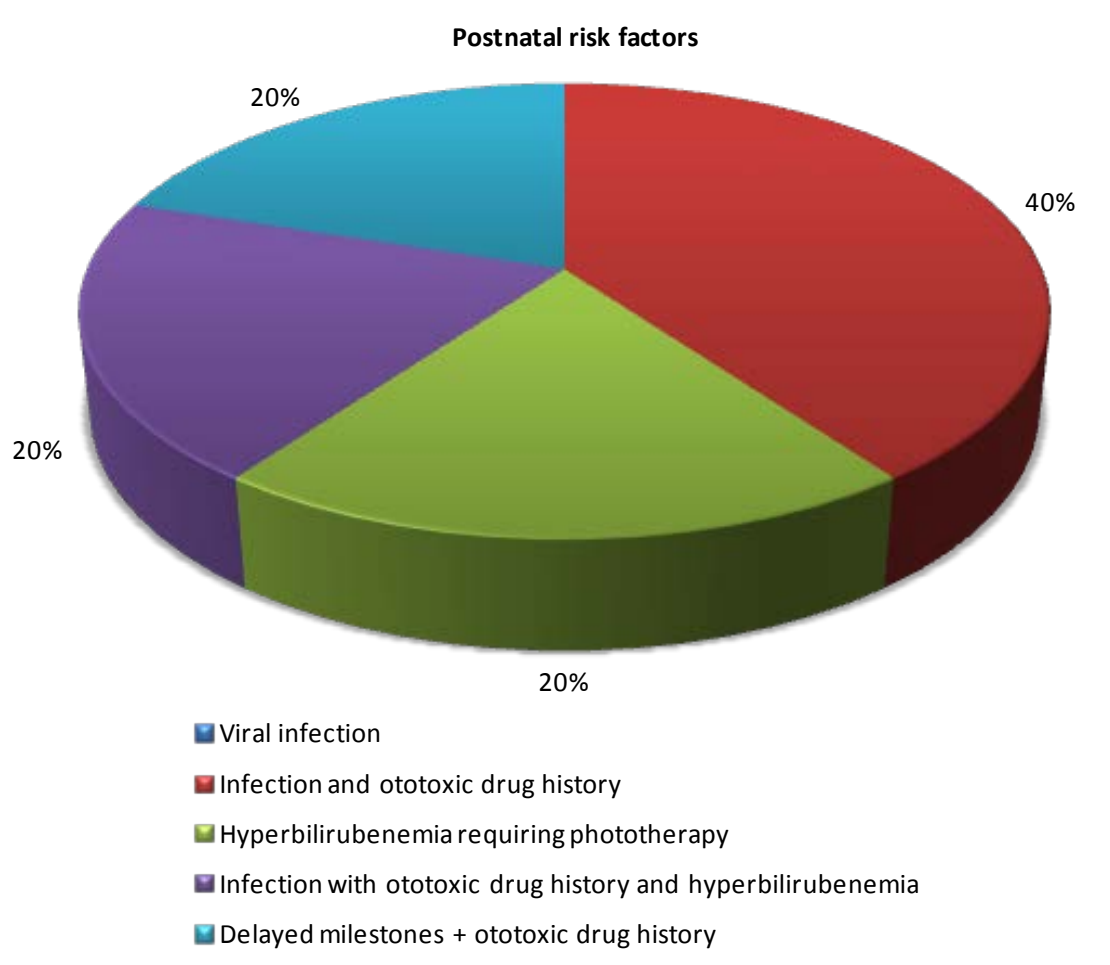

Figure 3. Postnatal risk factors. 
male to female ratio was 1.66 with males contributing $62.5 \%$ and females were $37.5 \%$; while in a study of 70 cases by Iype [2], male to female ratio was 1.06:1.

There is wide variation across the globe in the incidence and prevalence of childhood hearing loss and its possible etiology. The etiological diagnosis was obtained by means of an interview carried with the parents and family members. We approached relevant issues such as problems during pregnancy (prenatal factors), problems during delivery and birth of the baby (perinatal factors), problems during postnatal period and hereditary factors associated with the current disease.

The most common cause in our study was the acquired (56.66\%), corroborating with the prior studies reported by Iype [2], while Taylor [3] reported 41.86\% incidence of acquired causes. Studies by Fisch [4], Calhau [1] reported unknown cause as the most common factor. The second most contributing factor was the hereditary cause (26.66\%), corroborating with Billings [5], while Calhau [1] reported maternal rubella to be the second most common cause. The third cause is unknown (idiopathic), contributing to $16.66 \%$ of the deafness. Fraser [6] in 1960 from U.K reported that in $70 \%$ patients, the etiology was congenital and in 30\%, it was acquired. Strauss [7] in 1990 from USA reported that the probable cause of congenital deafness in their patients were toxoplasmosis $(10 \%-15 \%)$, rubella $(33 \%)$ and cytomegalovirus $(33 \%-48 \%)$. He further observed that with introduction of immunization program, the incidence of disease has decreased. As reported by Martin and Davis, the most frequent cause of acquired deafness in childhood was meningitis [8] [9] and according to Dodge [10], 5\% to 35\% of the patients with bacterial meningitis develop permanent sensorineural hearing loss..

In 34 cases out of 60, an acquired cause for deafness was found. Infant factor in the form of meningitis was found in 2 patients. Prenatal risk factors were identified in 14 cases (41.17\%) (Table 2), infection and ototoxic drug history was found to be the most common contributing factor $(42.85 \%)$, next common factors were history of repeated abortion (14.28\%) and preeclampsia (14.28\%). Serological test results were available for two cases which were positive for rubella infection (Table 3 ).

In 22 cases $(64.70 \%)$, perinatal risk factors were found, the most common cause was low birth weight followed by birth asphyxia and prematurity (Table 4). This is in concordance with the study carried out by Iype [2], in which prenatal risk factors were identified in $45.71 \%$, perinatal factors were found in $71.42 \%$. Birth asphyxia predisposed by prematurity and low birth weight was the most common perinatal risk factor. Majority of their neonatal group had jaundice requiring phototherapy and had delayed motor or personal social development. Bergman [11] found higher incidence of hearing loss in preterm babies than normal because of prolonged hypoxia or acidosis.

In the present study, postnatal risk factors were found in 10 cases $(29.41 \%)$, infection with history of ototoxic drugs was the most common contributing postnatal risk factors (60\%). Ototoxic drugs leading to hearing loss in our study were Gentamycin, Tobramycin and Amikacin, this is in concordance with study by Zahnert [12]. Delayed milestones were found in two patients (Table 5). In the study by Iype [2], neonatal risk factors along with antenatal or perinatal risk factors were found in 8 patients. Majority had neonatal jaundice requiring exchange transfusion (6 cases); of these a high proportion had delayed motor or personal social development.

3 patients of the study group had syndromic features with white forelock, dystopia canthorum and heterochromiairidis (Waardenburg's syndrome), contributing to 5\% and with the significant $\mathrm{P}$ value of 0.001 (Table 6). Zeitter [13] reported 3 (4.47\%) patients of Waardenburg's syndrome. In a study by Singh [14], syndromic hearing loss were found in 5.4\% patients of which, three cases were of Usher syndrome, four Waardenburg's syndrome, two Down syndrome and one patient of Treacher-collin syndrome.

S2-leitlinie, 2011 [15] reported that hearing impairment of genetic cause is due to congenital syndrome in $30 \%$ of cases and is nonsyndromic in $70 \%$. Among the nonsyndromic cases, the inheritance pattern is autosomal recessive in $70 \%-80 \%$, autosomal dominant in $10 \%-25 \%$, and X-linked in $2 \%-3 \%$. In our study of 16 cases of hereditary cause $18.75 \%$ were of syndromic group.

Nonsyndromic autosomal recessive hearing loss (the most common) is often due to a genetic mutation that impairs the synthesis of transmembrane proteins connexin 26 and 30, which in turn affects the ion transport mechanism in the hair cells and accordingly, connexin 26 and 30 mutations should be sought, whenever hearing impairment of genetic origin is suspected. Genetic hearing impairment is usually severe, being due to sporadic mutation and therefore hard to diagnose [16].

13 patients $(21.66 \%)$ (Table 1$)$ in the study group had familial deafness, including 9 patients with history of deafmutism in sibling, 2 patients with paternal and 2 with maternal history of deafmutism (Table 7 and Figure 4), while study by Singh (2009) [14] reported $10.8 \%$ cases of familial deafness. 


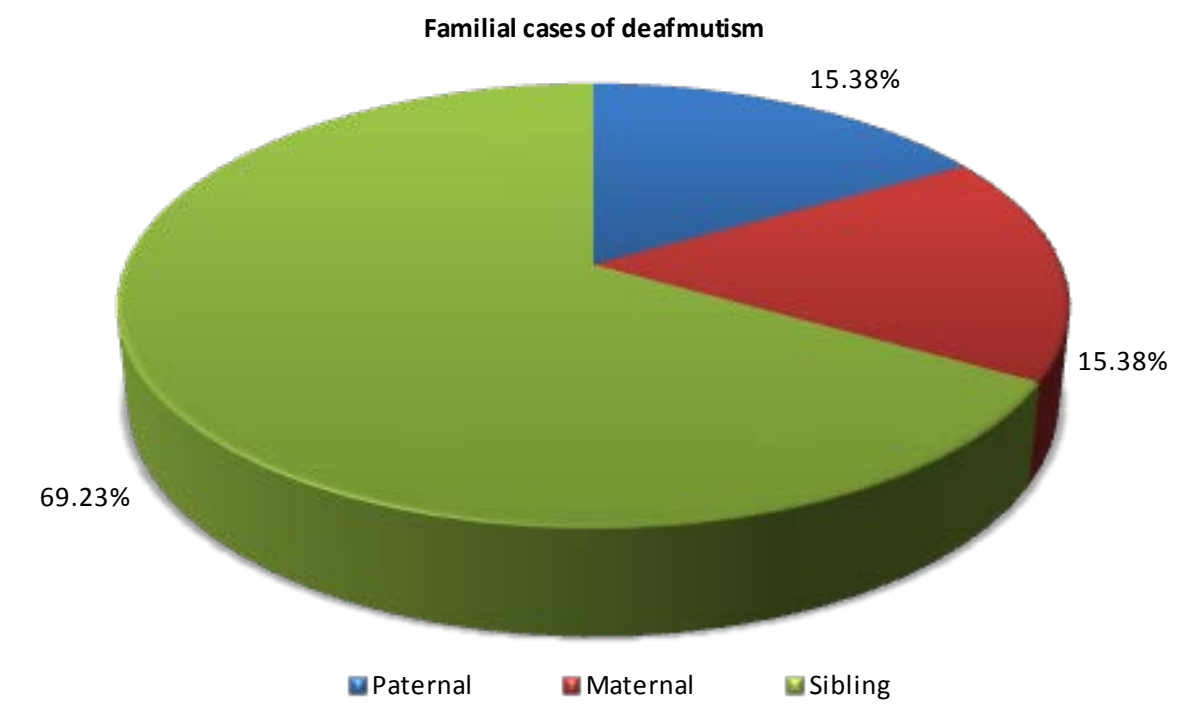

Figure 4. Distribution of familial cases of deafmutism.

\section{Summary and Conclusions}

The present study included 60 prelingually deafened patients who underwent cochlear implant in Department of Otorhinolaryngology, SMS Medical College, Jaipur. In this study, group perinatal risk factors were (64.7\%) most common followed by prenatal $(41.17 \%)$ and postnatal risk factors.

Infant factors were present in 2 cases $(5.88 \%)$. Low birth weight along with asphyxia and prematurity was most common perinatal cause. Infection and ototoxic drug history were most common causes in both prenatal and postnatal group. 3 patients (5\%) were of syndromic deafness while 13 patients $(21.66 \%)$ had familial deafness.

\section{References}

[1] Ferreira, C.C.M.D., Lima, J.L.R.P., et al. (2011) Etiology Profile of the Patients Implanted in the Cochlear Implant Program. Brazilian Journal of Otorhinolaryngology, 77, 13-18.

[2] Mathew, I.E., Sasikumaran, S. and Indira, D.S. (2000) A Clinical Study on Congenital and Neonatal Deafness. Indian Journal of Otolaryngology and Head and Neck Surgery, 52, 242-245.

[3] Taylor, I.G. (1980) The Prevention of Sensorineural Deafness. Journal of Laryngology and Otology, 94, 1327-1343.

[4] Fisch, I.G., Hine, W.D. and Brascer, V.J. (1975) A Study of the Causes of Hearing Loss in a Population of Deaf Children with Special Reference to Genetic Factors. The Journal of Laryngology and Otology, 89, 899-914. http://dx.doi.org/10.1017/S0022215100081184

[5] Billings, K.R. and Kenna, M.A. (1999) Causes of Pediatric Sensorineural Hearing Loss: Yesterday and Today. Arch Otolaryngol Head Neck Surg., 125, 517-521. http://dx.doi.org/10.1001/archotol.125.5.517

[6] Fraser, G.R., Froggatt, P. and James, T.N. (1964) Congenital Deafness Associated with Electrocardiographic Abnormalities, Fainting Attacks and Sudden Death. Quart J Med, 33, 361-385.

[7] Strauss, M. (1990) Human Cytomegalovirus Labyrinthitis. American Journal of Otolaryngology, 11, 292-329. http://dx.doi.org/10.1016/0196-0709(90)90057-3

[8] Martin, J.A.M. (1982) Aetiological Factors Relating to Childhood Deafness in the European Community. Audiology, 21, 149-158. http://dx.doi.org/10.3109/00206098209072735

[9] Davis, A.C., Wood (1992) The Epidemiology of Childhood Hearing Impairment: Factors Relevant to Planning of Services. British Journal of Audiology, 26, 77-90.

[10] Dodge, P.R., Davis, H., Feigin, R.D., et al. (1984) Prospective Evaluation of Hearing Impairment as a Sequela of Acute Bacterial Meningitis. The New England Journal of Medicine, 311, 869-874.

[11] Bergman, L., Hirsch, R.P., Fria, T.J., Shapiro, S.M., Holzman, I. and Painter, M.J. (1985) Cause of Hearing Loss in the High-Risk Premature Infant. The Journal of Pediatrics, 106, 95-101.

http://dx.doi.org/10.1016/S0022-3476(85)80476-5 
[12] Zanhert, T. (2011) The Differential Diagnosis of Hearing Loss. Deutsches Arzteblatt International, 108, 433-444.

[13] Zeitler, D.M., Anwar, A., et al. (2012) Cochlear Implantation in Prelingually Deafened Adolescents. Archives of Pediatrics and Adolescent Medicine, 166, 35-41. http://dx.doi.org/10.1001/archpediatrics.2011.574

[14] Singh, M., Gupta, S.C. and Singla, A. (2009) Assessment of Deafmute Patients: A Study of Ten Years. Indian Journal of Otolaryngology and Head \& Neck Surgery, 61, 19-22. http://dx.doi.org/10.1007/s12070-009-0027-3

[15] S2-Leitlinie (2011) Periphere Horstorungen im Kindesalter. AWMF-Register Number 049/010, Stand 02/2005. www.awmf.org/uploads/tx_szleitlinien/049-0101.pdf

[16] Ptok, M. and Ptok, A. (2001) Formen kindlicher Schwerhorigkeit. Monatsschr Kinderheilkd, 149, 870-876. 